\title{
New method for typing Staphylococcus aureus resistant to methicillin based on sulphur-35 methionine labelled proteins: its application in an outbreak
}

\author{
J R STEPHENSON, S J CROOK, S TABAQCHALI
}

\begin{abstract}
Sodium dodecyl sulphate polyacrylamide gel electrophoresis of sulphur-35 methionine labelled cellular proteins of Staphylococcus aureus resistant to methicillin was used as a typing method during an outbreak on a cardiothoracic ward. This showed that the outbreak strain was indistinguishable from the epidemic strain of methicillin resistant $S$ aureus prevalent in London. In contrast, 44 epidemiologically separate strains of $S$ aureus gave individually distinct radiolabelled protein profiles.

This method permitted rapid confirmation that an epidemic strain was responsible and indicated the need for urgent control measures.
\end{abstract}

\section{Introduction}

Outbreaks of infection with Staphylococcus aureus resistant to methicillin have recently increased in the United Kingdom, in particular in London hospitals.' ' Management of these outbreaks is difficult, because control of cross infection with this organism often requires the use of separate isolation units ${ }^{3}{ }^{4}$ and treatment is usually confined to a single antibiotic, vancomycin, although newer antibiotics are being developed. An outbreak can be suggested by a cluster of isolates of $S$ aureus resistant to methicillin, but confirmation requires typing of these isolates. The epidemic strain of methicillin resistant $S$ aureus prevalent in the south east of England does not usually react with the international set of phages but can be distinguished from other strains by its reaction with additional phages and its pattern of resistance to antibiotics. ${ }^{2}$ The introduction of a rapid simple method for typing isolates of methicillin resistant $S$ aureus would therefore be useful in detecting outbreaks and would

\footnotetext{
Department of Medical Microbiology, St Bartholomew's Hospital Medical College, London EC1A 7BE

J R STEPHENSON, MA, MB, lecturer

S J CROOK, MB, MRCPATH, senior registrar

S TABAQCHALI, MB, FRCPATH, professor

Correspondence to: Dr Stephenson.
}

act as an additional marker for determining whether the same strain is causing all the outbreaks in the United Kingdom.

We developed a typing scheme using sodium dodecyl sulphate polyacrylamide gel electrophoresis of radiolabelled proteins of $S$ aureus and applied it to the strains isolated during an outbreak on the cardiothoracic ward at St Bartholomew's Hospital. In addition, to assess this method we also tested selected groups of $S$ aureus obtained from the Public Health Laboratory Service and compared the method to existing typing methods.

\section{Methods}

The cardiothoracic surgical ward has a main ward containing 10 beds and a four bed recovery unit. The ward also has four single rooms and one double room, which were used during the outbreak for barrier nursing of patients who yielded isolates of methicillin resistant $S$ aureus.

\section{BACTERIOLOGICAL SAMPLING}

Screening swabs were moistened with saline before sampling and were cultured on nutrient agar (Oxoid) containing $2 \mathrm{mg}$ gentamicin/1 with incubation at $37^{\circ} \mathrm{C}$ overnight. Staphylococci were tested for tube coagulase production and susceptibility to methicillin. Isolates of methicillin resistant $S$ aureus were stored at $-20^{\circ} \mathrm{C}$ in $2 \mathrm{ml}$ volumes of nutrient broth (containing $1.6 \mathrm{ml}$ Oxoid nutrient broth $\mathrm{No} 2$ and $0.4 \mathrm{ml}$ glycerol) and were sent to the Division of Hospital Infection, Public Health Laboratory Service, for phage typing. They were also tested by electrophoresis after being radiolabelled.

The Division of Hospital Infection supplied 55 epidemiologically assorted strains of $S$ aureus in five equal groups: "epidemic" methicillin resistant $S$ aureus; "other" methicillin resistant $S$ aureus; other resistant (methicillin sensitive) $S$ aureus; "sensitive" $S$ aureus (some of these strains were resistant only to penicillin or tetracyclines, or both); and a miscellaneous group, mainly of animal strains of $S$ aureus. These strains were coded, run at random, and analysed blind.

\section{TYPING METHOD}

For the electrophoretic procedure strains were subcultured from storage on to horse blood agar (Gibco) and incubated 6vernight at $37^{\circ} \mathrm{C}$. Portions of three colonies of each strain were inoculated into $50 \mu \mathrm{l}$ volumes of 
methionine assay medium (Difco) containing $185 \mathrm{kBq}(5 \mu \mathrm{Ci})$ of sulphur-35 methionine (Amersham International) until the medium appeared slightly turbid. The samples were incubated at $37^{\circ} \mathrm{C}$ in air for three hours, and subcultures were then made to check the purity. Enzymatic digestion of the staphylococcal cell wall was achieved by adding $50 \mu$ l volumes of lysostaphin solution containing $400 \mathrm{mg}$ lysostaphin (Sigma Chemicals) $/ 1$ in $10 \mathrm{mM}$ trometamol buffer and reincubating the samples at $37^{\circ} \mathrm{C}$ for 45 minutes. Then $100 \mu \mathrm{l}$ volumes of double strength sample buffer were added ${ }^{5}$ and the soluble proteins were dissociated by immersing the samples for three minutes in boiling water.

Sodium dodecyl sulphate polyacrylamide gel electrophoresis was performed according to the method of Laemmli, ${ }^{5}$ with a stacking gel containing $30 \mathrm{~g}$ acrylamide $/ 1$ and a resolving gel containing $100 \mathrm{~g}$ acrylamide $/ 1$ at 0.75 $\mathrm{mm}$ thickness. On each gel 12 samples and one aliquot of carbon-14 methylated protein mixture (Amersham International) were loaded in $15 \mu \mathrm{l}$ volumes. Electrophoresis was carried out at constant current using $10 \mathrm{~mA} /$ gel for stacking and continued at $15 \mathrm{~mA} / \mathrm{gel}$ throughout the resolving gel The gels were fixed overnight in an aqueous solution containing $200 \mathrm{ml}$ glacial acetic acid and $200 \mathrm{ml}$ propan-2-ol in each litre, and then vacuum dried on to filter paper. Autoradiographs were developed after 24 hours exposure. Comparison of the labelled protein profiles was performed visually after the autoradiographs had been cut into strips of two lanes each.

\section{Results}

A cluster of four patients on the cardiothoracic ward who yielded isolates of methicillin resistant $S$ aureus was detected by surveillance of laboratory reports in late April 1985. All patients and staff on the ward were screened on 29 April by taking nose swabs. This yielded one new positive patient (case 5). Antibiotic prophylaxis for all cardiothoracic surgery was changed from flucloxacillin and gentamicin to vancomycin and gentamicin. All colonised patients were isolated and given chlorhexidine based antiseptics for washing and to be applied to their noses. Despite these measures four new cases occurred during the next week, and a second screen of all patients and staff was performed, with samples being taken from the nose, axilla, groin, perineum, and skin lesions. This extended screening did not detect any new cases, and so we advised that all patients and staff on the ward should use chlorhexidine preparations for washing hair and skin and for nasal application. After two weeks, as no further cases had occurred, these measures were stopped.

The outbreak affected nine patients, of whom five were infected clinically at sites shown in the table. All the strains isolated from these nine patients reacted with experimental phages and resembled the epidemic methicillin resistant $S$ aureus.

Sites at which methicillin resistant $S$ aureus detected

\begin{tabular}{cll}
\hline $\begin{array}{c}\text { Case } \\
\text { No }\end{array}$ & \multicolumn{1}{c}{ Site } & $\begin{array}{c}\text { Appreciable } \\
\text { infection }\end{array}$ \\
\hline 1 & Liver, empyema, blood & Yes \\
2 & Sternum, blood & Yes \\
3 & Left and right leg & No \\
4 & Wound & Yes \\
5 & Nose & No \\
6 & Chest drain & No \\
7 & Wound & Yes \\
8 & Wound & No \\
9 & Pacemaker, blood & Yes \\
\hline
\end{tabular}

A pilot study using 26 strains of methicillin sensitive $S$ aureus that had already been phage typed indicated provisional criteria for discrimination in the electrophoretic procedure. Strains were typed as being different if one strain either had one or more radiolabelled protein bands of different molecular weight or had two or more bands of the same molecular weight but with pronounced differences in intensity.

All nine isolates of methicillin resistant $S$ aureus from the outbreak at $S t$ Batholomew's Hospital were indistinguishable by the electrophoretic technique (fig 1), suggesting that it was the same strain that had caused cross infection. Among the strains from the Division of Hospital Infection 10 were found to be indistinguishable, and these were all epidemic methicillin resistant strains. One strain sent as an epidemic strain seemed to be different by our method, but on retesting by phage typing it was found not to be an epidemic strain. All the $\mathbf{4 4}$ other strains gave individually distinct radiolabelled protein profiles, and this agreed with their separate phage typing patterns. Figure 2 shows an example of an autoradiograph.

The strains isolated during the hospital outbreak were indistinguishable from the epidemic methicillin resistant strains from the Public Health Laboratory Service by the electrophoretic technique.

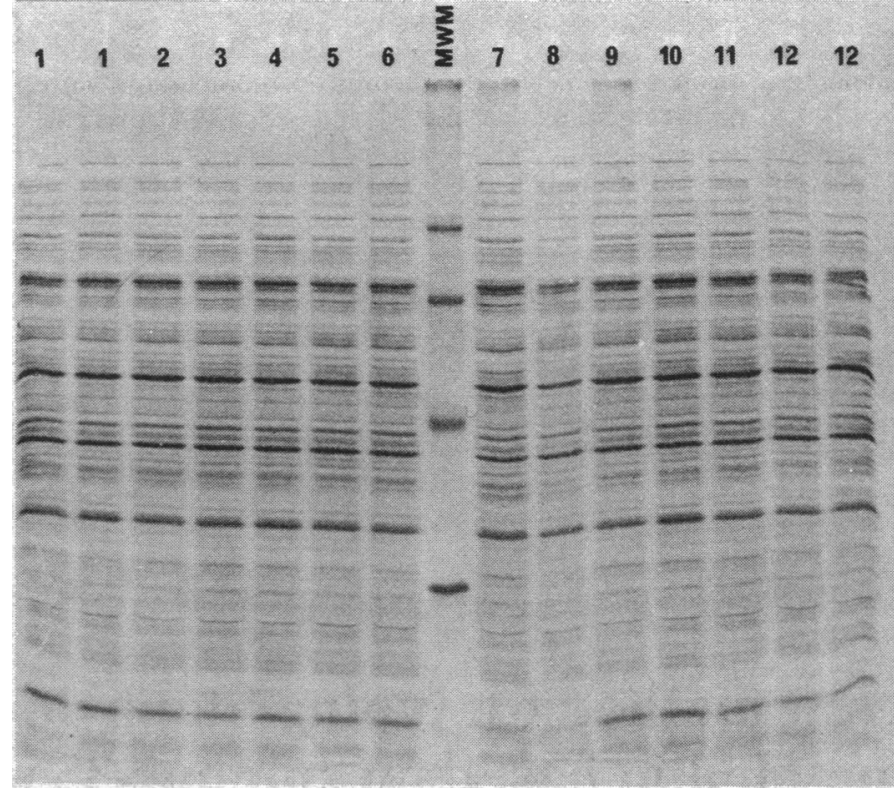

FIG 1-Autoradiograph of epidemic strains of methicillin resistant $S$ aureus isolated during outbreak at St Bartholomew's Hospital (lanes 1-5, 9-12) and supplied by Division of Hospital Infection, Public Health Laboratory Service (lanes 6-8).

MWM=Molecular weight markers: $200,93,69,46,30$, and 14 kilodaltons.

\section{Discussion}

Whole cell polyacrylamide gel electrophoresis of bacteria, without radiolabelling, is a well established technique in microbial methods. ${ }^{6}$ The resolution of the protein bands after staining, however, is inferior to that obtained by autoradiography of radiolabelled protein bands. This technique was first applied as a typing method during an outbreak of diarrhoea due to Clostridium difficile at this hospital. ${ }^{7}$ This paper describes the extension of this technique to type $S$ aureus. Typing systems can be assessed by three main characteristics—-namely, typability, reproducibility, and dis-

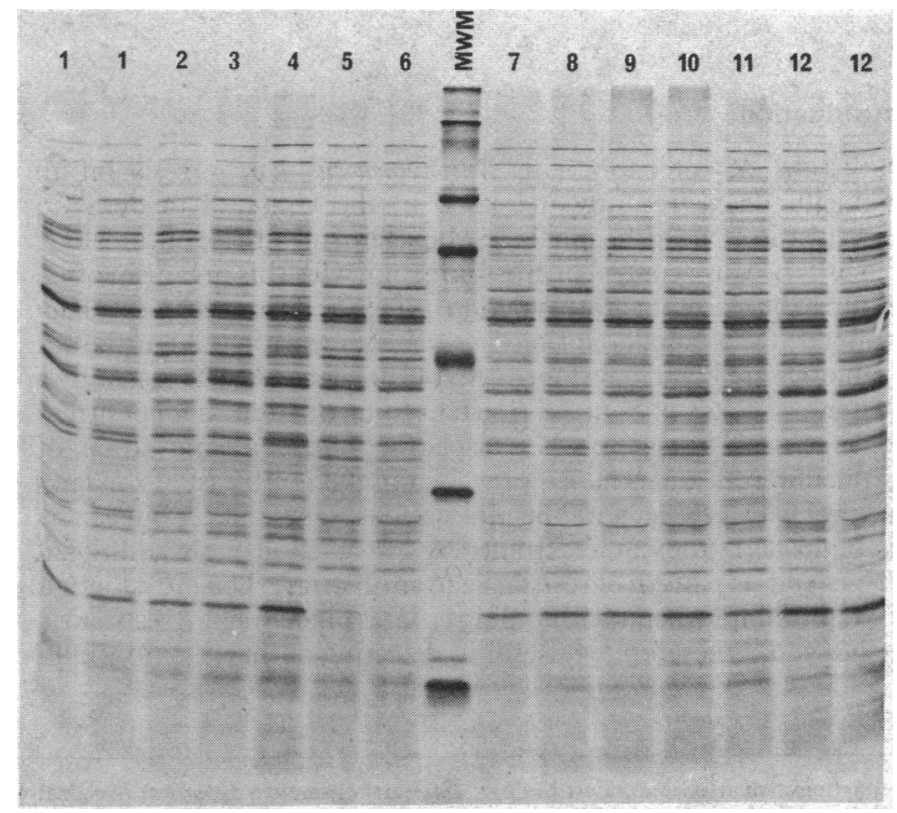

FIG 2-Autoradiograph of various representative strains of $S$ aureus from Division of Hospital Infection, Public Health Laboratory Service. Lanes 5, 6: epidemic methicillin resistant $S$ aureus. Lanes 1, 2, 3, 7, 9, 12: other methicillin resistant $S$ aureus. Lane 10: other resistant (methicillin sensitive) $S$ aureus. Lanes $4,8,11$ : strain sensitive, or resistant, to only penicillin or tetracyclines, or both.

MWM = Molecular weight markers: $200,93,69,46,30$, and 14 kilodaltons. 
crimination. Typability is excellent with electrophoresis of radiolabelled bacteria, as all strains tested in this study produced a clear radiolabelled protein profile. Reproducibility is comparable with that of other typing methods in which strains to be tested must be labelled and run in the same batch. Comparison between strains is optimal if they are run on the same gel; indeed, two strains of epidemic methicillin resistant $S$ aureus were initially read as different when compared on different gels but when rerun on the same gel were indistinguishable from the other epidemic strains. At present typing by electrophoresis of radiolabelled bacteria relies on comparison with known isolates of epidemic methicillin resistant $S$ aureus, although future computer assisted analysis is planned. Discrimination seems, from this limited number of strains, to be equivalent to that of phage typing for the non-epidemic strains.

Polyacrylamide gel electrophoresis of radiolabelled isolates from the hospital outbreak provided rapid confirmation that an epidemic strain of methicillin resistant $S$ aureus was responsible and thus that urgent control measures were necessary. This outbreak is an example of the increasing problem of methicillin resistant $S$ aureus in London hospitals recently. ${ }^{28}$ The explanation for its fairly short duration is not clear but may be the fact that we treated all patients and staff rather than just those who were culture positive. ${ }^{9}$ The finding that the epidemic strains of methicillin resistant $S$ aureus are indistinguishable by electrophoresis after radiolabelling adds further evidence that they may be essentially one single strain, as has been suggested for isolates found in London and Australia. ${ }^{8} 1011$
We thank Mr G M Rees and Mr S J Edmondson for allowing us to present clinical details of patients under their care. We also thank Professor E M Cooke and Dr R R Marples for help and advice. We are grateful to the Division of Hospital Infection for providing strains for this study.

\section{References}

1 Anonymous. What's to be done about resistant staphylococci? [Editorial]. Lancet 1985;ii:189-90. 2 Marples RR, Cooke EM. Report of workshop on methicillin-resistant Staphylococcus aureus held at the headquarters of the Public Health Laboratory Service on 8 January 1985. 7 Hosp Infect 1985;6:342-8.

3 Selkon JB, Stokes ER, Ingham HR. The role of an isolation unit in the control of hospital infection with methicillin-resistant staphylococci. J Hosp Infect 1980;1:41-6.

4 Pearman JW, Christiansen KJ, Annear DI, et al. Control of methicillin-resistant Staphylococcus aureus (MRSA) in an Australian metropolitan teaching hospital complex. Med f Aust 1985;142:103-8

5 Laemmli UK. Cleavage of structural proteins during the assembly of the head of bacteriophage T4. Nature 1970;227:680-5.

6 Kersters K, De Ley J. Classification and identification of bacteria by electrophoresis of their proteins. In: Goodfellow M, Board RG, eds. Microbiological classification and identification. London: Academic Press, 1980.

7 Tabaqchali S, Holland D, O'Farrell S, Silman R. Typing scheme for Clostridium difficile: its application in clinical and epidemiological studies. Lancet 1984;i:935-8.

8 Bradley JM, Noone P, Townsend DE, Grubb WB. Methicillin-resistant Staphylococcus aureus in a London hospital. Lancet 1985;i:1493-5.

9 Bartzokas CA, Paton JH, Gibson MF, Graham R, McLoughlin GA, Croton RS. Control and eradication of methicillin-resistant Staphylococcus aureus on a surgical unit. $N$ Engl $\mathcal{F} \mathrm{Med}$ 1984;311:1422-5.

10 Gedney J, Lacey RW. Properties of methicillin-resistant staphylococci now endemic in Australia. Med F A ust 1982;1:448-50.

1 Townsend DE, Ashdown N, Bradley JM, Pearman JW, Grubb WB. "Australian" methicillinresistant Staphylococcus aureus in a London hospital? Med f Aust 1984;141:339-40.

Accepted 13 fune 1986

\title{
Traditional Chinese acupuncture: a potentially useful antiemetic?
}

\author{
J W DUNDEE, W N CHESTNUTT, R G GHALY, A G A LYNAS
}

\begin{abstract}
Two consecutive studies were undertaken to evaluate the effectiveness of acupuncture as an antiemetic used in addition to premedication with opioids in patients undergoing minor gynaecological operations. In the first study 25 of the 50 patients underwent acupuncture immediately after premedication with $100 \mathrm{mg}$ meptazinol, the rest receiving the drug alone, and in the second 75 patients were allocated randomly to one of three groups: a group receiving $10 \mathrm{mg}$ nalbuphine and acupuncture, a group receiving premedication and dummy acupuncture, and a group receiving premedication alone. Manual needling for five minutes at the P6 acupuncture point (Neiguan) resulted in a significant reduction in perioperative nausea and vomiting in the 50 patients who underwent acupuncture compared with the 75 patients who received no acupuncture.

These findings cannot be explained, but it is recommended that the use of acupuncture as an antiemetic should be explored further.
\end{abstract}

\section{Introduction}

Despite improvements in anaesthetic techniques perioperative vomiting still remains a problem, particularly in ambulant outpatients, in children, and when an opioid is given before or during anaesthesia. ${ }^{12}$ Antiemetics are of limited value and often cause drowsiness or other side effects. ${ }^{3}$

On a visit to the People's Republic of China one of us (JWD) was impressed by the use of acupressure as prophylaxis against vomiting in early pregnancy. At the antenatal clinic women were instructed to press the point Neiguan (P6), just above the right wrist. This is described as a treatment for hyperemesis gravidarum in an English textbook on acupuncture, ${ }^{4}$ but there is no evidence to support the claim. If it could be applied to anaesthetic practice it would be a nontoxic and inexpensive treatment that might be useful in other fields.

We report on two consecutive studies in which a simple traditional Chinese acupuncture procedure was used in addition to opioid premedication in patients undergoing a minor operation under standard anaesthesia. As far as possible the same criteria were applied to these studies as to the evaluations of recognised antiemetic drugs. ${ }^{356}$

The studies were approved by the local medical ethical research committee, and patients gave verbal consent to participate in studies with premedicants, but no reference was made to nausea or vomiting.

\section{Patients and methods}

All of the patients were fit women aged $16-60$ and weighing $40-80 \mathrm{~kg}$, who were to undergo minor gynaecological operations during the same morning. Two studies were carried out in gynaecological units. In the first $100 \mathrm{mg}$ meptazinol was given intramuscularly as premedication, and in the second $10 \mathrm{mg}$ nalbuphine was given. Half of the 50 patients in the first study

\footnotetext{
Department of Anaesthetics, The Queen's University of Belfast

JW DUNDEE, MD, professor

R G GHALY, FFARCS, lecturer

Correspondence to: Professor J W Dundee, Department of Anaesthetics, Whitla Medical Building, 97 Lisburn Road, Belfast BT9 7BL.
} 